\title{
Genetic diversity of $F 1$ and $F 2$ interspecific hybrids between dwarf birch (Betula nana L.) and Himalayan birch (B. utilis var. jacquemontii (Spach) Winkl. 'Doorenbos') using RAPD-PCR markers and ploidy analysis*
}

\author{
Małgorzata Czernicka ${ }^{\circledR}$, Jarosław Pławiak ${ }^{1}$ and Piotr Muras ${ }^{2}$ \\ IInstitute of Plant Biology and Biotechnology, ${ }^{2}$ Department of Dendrology and Landscape Architecture, University of Agriculture in Krakow, \\ Kraków, Poland
}

\begin{abstract}
Crosses between Betula nana and B. utilis 'Doorenbos' were undertaken in order to obtain interspecific hybrids which could be characterized by wide spreading stems, strong branching habit, decorative clear white bark and an interesting shape of purple leaves. The research purpose was to examine genetic diversity of the $16 \mathrm{~F} 1$ and F2 putative progenies by using the RAPD-PCR method and the ploidy analysis. A total of 242 RAPD markers were scored with 24 primers and 220 (90.9\%) polymorphic bands were found. In the NJ dendrogram, cluster I consisted of the female parent - B. nana and 12 hybrids and cluster II grouped the male parent $-B$. utilis 'Doorenbos' with 4 hybrids (F2/2, F1/8, F1/7 and F2/1). The 2-D scaling by PCoA was in agreement with the similarity index, i.e. two hybrids (F1/8, F2/2) grouped with the male parent while others with female parent. Classification of the hybrid plants by chromosome counting demonstrated that 13 hybrids were confirmed with accurate chromosome counts as being diploid $(2 n=2 x=28)$ and 3 plants (F1/7, F1/8, F2/2) as triploid with 42 chromosomes.
\end{abstract}

Key words: Betula nana, Betula utilis 'Doorenbos', interspecific hybrids, ploidy analysis, RAPD-PCR

Received: 15 October, 2013; revised: 06 April, 2014; accepted: 17 April, 2014; available on-line: 06 June, 2014

\section{INTRODUCTION}

The number of species belonging to the genus Betula L., commonly known as birch, is estimated to be between 30-60 taxa (Järvinen et al., 2004) distributed throughout northern temperate regions (Atkinson, 1992). In Europe, three species are recognized: silver birch (B. pendula Roth.), downy birch (B. pubescens Ehrh.) and dwarf birch (B. nana L.) (de Groot et al., 1997).

Betula nana L., a highly branched shrub growing up to $1 \mathrm{~m}$ in height, is widespread in the Arctic regions of Eurasia, Greenland, Iceland and North America. In Central and Eastern Europe the dwarf birch is an endangered species, a glacial relict that is still present in three localizations in the Alps and the Carpathians (Jadwiszczak et al., 2012). In Poland, B. nana occurs in three isolated reserves: "Torfowisko pod Zieleńcem" (Sudety Mts.), "Torfowiska Doliny Izery" (Sudety Mts.) and "Linje" in Northern Poland (Ejankowski \& Kunz, 2006).
The basic chromosome number of Betula is $\mathrm{x}=14$ but within that genus a variety of taxa with ploidy levels ranging from $2 n=2 x=28$ up to $2 n=10 x=140$ can be found (Furlow, 1990). Polyploidy among Betula species suggests several independent polyploidization events. Hybridization and introgression are common while the natural distributions of birch species overlap, i.e. among the European birch species B. pendula, B. pubescens and B. nana (Thorsson et al., 2007). Moreover, several Betula species have a hybrid origin. Hybrids generally show intermediate morphology between the parental species but are not always morphologically distinct as a group. This overlap in morphological features complicates species and hybrid identification. Hybridization and introgression are further facilitated by the introduction and distribution of propagated cultivars outside the natural distribution range (Schenk et al., 2008).

In our research, interspecific hybridization between B. nana L. x B. utilis var. jacquemontii (Spach) Winkl. 'Doorenbos' was undertaken with the objective of combining the desirable traits, such as wide spreading stems, strong branching habit, decorative clear white bark and an interesting shape of leaves. Chromosome numbers in B. nana and B. utilis 'Doorenbos' are $2 \mathrm{n}=28$ and $2 \mathrm{n}=56$, respectively (Eaker et al., 2007; Thorsson et al., 2007), therefore hybrids were expected to have $2 n=42$. Since the traditional method of hybrid identification based on morphological character is influenced by environmental factors and frequently lacks the resolving power to identify hybrids at the juvenile stage, it was necessary to introduce far more distinct analytical methods. Generally, F1 hybrids contain DNA from both parents and molecular markers identify both male and female parentspecific markers allowing differentiation of true hybrids from selfed individuals and outcrossed individuals with foreign pollen. Molecular markers generated from randomly amplified polymorphic DNA (RAPD) (Williams et al., 1990) have been used to study genetic diversity and to confirm hybrids and their parental species, such as in B. alleghaniensis (Roy et al., 1992), B. alnoides (Zeng et al., 2003), B. maximowicziana (Tsuda et al,. 2004), and B. nana (Dąbrowska et al., 2006).

e-mail: m.czernicka@ogr.ur.krakow.p

* Preliminary report was presented at the 5th Central European Congress of Life Sciences EUROBIOTECH 2013, 8-11 October 2013, Kraków, Poland

Abbreviations: RAPD, randomly amplified polymorphic DNA; PCoA, principal coordinates analysis; NJ, Neighbor-Joining 
The objective of this study was to assess the genetic diversity at genotypic level. For these purposes, randomly amplified polymorphic DNA (RAPD-PCR) marker system and ploidy analysis determined by chromosome counting were applied.

\section{MATERIALS AND METHODS}

Plant materials. Plant materials were parental taxa, i.e. B. nana and B. utilis 'Doorenbos', 8 putative F1 hybrids, 8 putative F2 hybrids. All of these plants were grown in the collection of ornamentals held by Piotr Muras (Tomaszkowice near Kraków). Controlled pollinations were performed in 2001 when the female inflorescences of $B$. nana were manually pollinated by $B$. utilis 'Doorenbos' pollen. Flowers were pollinated at least twice at 2-day intervals. Seeds were collected and stored at $3^{\circ} \mathrm{C}$ until sowing. They were germinated in March 2002. The F1 plants were allowed to self-pollinate in order to obtain F2 progenies.

RAPD analysis. Total genomic DNA was extracted from juvenile leaves using DNeasy Plant Mini Kit (Qiagen). The purity and quantity of the isolated DNA was determined by Nanodrop spectrophotometry (Thermo
Scientific). PCR reaction mixtures of $20 \mu \mathrm{l}$ contained $5 \mathrm{ng}$ of template DNA, $1 \times$ Taq buffer with $\mathrm{KCl}($ Fermentas), $2 \mathrm{mM} \mathrm{MgCl}_{2}, 0.25 \mathrm{mM}$ dNTPs, $0.5 \mu \mathrm{M}$ 10-mer primer and 1 unit of recombinant Taq polymerase (Fermentas). Amplifications were carried out in an Eppendorf Mastercycler Gradient, running at $94^{\circ} \mathrm{C}$ for $3 \mathrm{~min}$, then 40 cycles of $93^{\circ} \mathrm{C}$ for $1 \mathrm{~min}, 42^{\circ} \mathrm{C}$ for $1 \mathrm{~min}$ and $68^{\circ} \mathrm{C}$ for $2.5 \mathrm{~min}$, followed by $72^{\circ} \mathrm{C}$ for $5 \mathrm{~min}$. The PCR products were separated in 1\% agarose gels containing $0.5 \mu \mathrm{g} \mathrm{ml}^{-1}$ ethidium bromide. Electrophoresis was undertaken in TBE buffer for $2 \mathrm{~h}$ at a field strength of $4 \mathrm{~V} \times \mathrm{cm}^{-1}$. The DNA fingerprints were visualized under ultraviolet light and photographed with a CCD camera. Thirty random decamer primers were tested but only those primers that produced reproducible amplified bands were scored for presence or absence of each fragment for each single plant. Program GenAlEx ver. 6.41 was used to analyze the data and visualize population structure (Peakall \& Smouse, 2006). A set of genetic measures included: observed number of alleles $(A a)$, effective number of alleles (Ae), Nei's (1973) gene diversity $(H)$, Shannon's Information Index $(I)$ and number of polymorphic bands. A dendrogram based on Nei's genetic distance matrix was constructed using the Neighbor-Joining method through the Phylip software ver.

Table 1. Summary of amplification patterns generated by random primers selected for RAPD analysis

\begin{tabular}{|c|c|c|c|c|c|c|c|}
\hline \multirow[b]{2}{*}{ Primer } & \multirow{2}{*}{$\begin{array}{l}\text { Sequence } \\
\qquad\left(5^{\prime} \rightarrow 3^{\prime}\right)\end{array}$} & \multicolumn{3}{|c|}{ Number of bands } & \multirow{2}{*}{$\begin{array}{l}\text { Polymorphism } \\
(\%)\end{array}$} & \multicolumn{2}{|c|}{ Size of bands (bp) } \\
\hline & & total & polymorphic & $\begin{array}{l}\text { specific for } \\
\text { B. utilis 'Doorenboos' }\end{array}$ & & $\min$ & $\max$ \\
\hline OPA01 & CAGGCCCTTC & 10 & 10 & 1 & 100 & 350 & 2000 \\
\hline OPA02 & TGCCGAGCTG & 11 & 10 & 3 & 90.9 & 300 & 3000 \\
\hline OPA03 & AGTCAGCCAC & 12 & 7 & 1 & 58.3 & 430 & 3000 \\
\hline OPA08 & GTGACGTAGG & 11 & 11 & 1 & 100 & 740 & 2900 \\
\hline OPA09 & GGGTAACGCC & 11 & 10 & 4 & 90.9 & 310 & 3200 \\
\hline OPA10 & GTGATCGCAG & 9 & 8 & 1 & 88.9 & 520 & 2300 \\
\hline OPA11 & CAATCGCCGT & 10 & 10 & 1 & 100 & 280 & 3000 \\
\hline OPA12 & TCGGCGATAG & 14 & 14 & 3 & 100 & 310 & 3500 \\
\hline OPA15 & TTCCGAACCC & 12 & 11 & 3 & 91.7 & 330 & 3500 \\
\hline OPA17 & GACCGCTTGT & 11 & 11 & 1 & 100 & 700 & 3000 \\
\hline OPA20 & GTTGCGATCC & 11 & 11 & 3 & 100 & 350 & 3200 \\
\hline OPB01 & GTTTCGCTCC & 9 & 9 & 1 & 100 & 360 & 3000 \\
\hline ARD1 & TITGCCCGGA & 12 & 12 & 2 & 100 & 950 & 3500 \\
\hline ARD3 & CCACAGCAGT & 11 & 6 & 3 & 54.5 & 350 & 3200 \\
\hline ARD4 & AGCCAGCGAA & 10 & 10 & 2 & 100 & 500 & 3000 \\
\hline ARD5 & CAAACGTTGT & 11 & 11 & 3 & 100 & 980 & 3500 \\
\hline ARD6 & CAAACGTCGG & 4 & 3 & 2 & 83.3 & 900 & 2500 \\
\hline ARD10 & GGACCCTTAC & 18 & 17 & 2 & 94.4 & 300 & 3500 \\
\hline ARD15 & ACTTCGCCAC & 5 & 3 & 1 & 60.0 & 400 & 900 \\
\hline ARD20 & ACCCGGTCAC & 7 & 6 & 0 & 85.7 & 480 & 1800 \\
\hline ARK4 & GAAACGGGTG & 7 & 6 & 4 & 85,7 & 500 & 2900 \\
\hline ARK6 & CTGCTGGGAC & 10 & 9 & 0 & 90.0 & 480 & 3500 \\
\hline ARK7 & GTAGACCCGT & 6 & 5 & 2 & 87.5 & 750 & 1900 \\
\hline ARK11 & GTCGCCGTCA & 10 & 10 & 5 & 100 & 600 & 2000 \\
\hline \multicolumn{2}{|c|}{ Total number of bands } & 242 & 220 & 49 & 90.9 & - & - \\
\hline \multicolumn{2}{|c|}{$\begin{array}{l}\text { Average number of bands } \\
\text { per primer }\end{array}$} & 10.1 & 9.2 & 2.0 & - & - & - \\
\hline
\end{tabular}




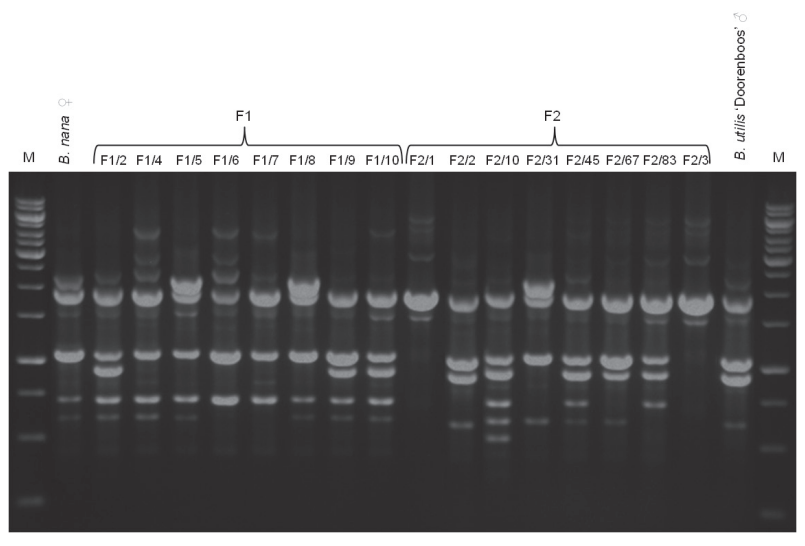

Figure 1. Gel image showing RAPD profile obtained by OPA10 primer.

Lane 1 and 17 represent parental genotypes

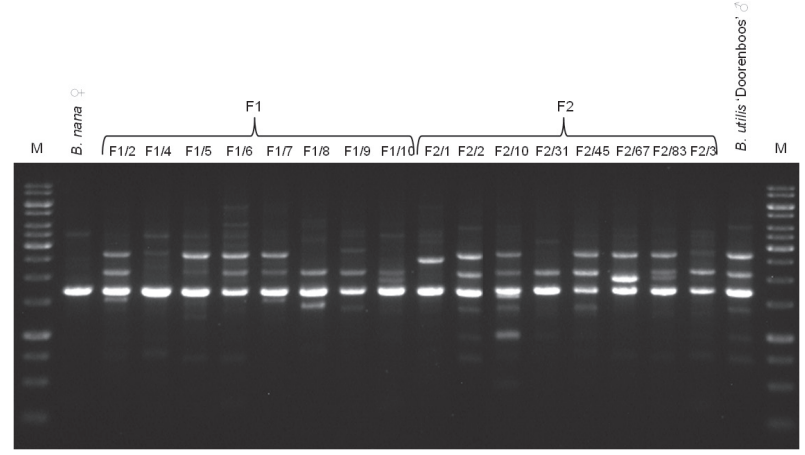

Figure 2. Gel image showing RAPD profile obtained by ARK7 primer.

Lane 1 and 17 represent parental genotypes

3.65 (Felsenstein, 2005). PCoA was also done to check the results of Neighbor-Joining based clustering using Eigen module of GenAlEx ver. 6.41.

Chromosome analysis. Mitotic chromosomes were isolated from young leaf buds using the protoplast dropping method of Anamthawat-Jónsson (2003). The buds were collected in iced water and treated for $24 \mathrm{~h}$ to arrest metaphases before fixing in a mixture of absolute ethanol and glacial acetic acid (3:1). The fixed buds were digested in an enzyme mixture of $2.5 \%(\mathrm{w} / \mathrm{v})$ cellulase Onozuka R10 (Merck) and 2.5\% (v/v) pectinase (Sigma-Aldrich) for $16-20 \mathrm{~h}$ at room temperature. After hypotonic treatment with $75 \mathrm{mM} \mathrm{KCl}$ solution for 5-10 $\mathrm{min}$, and repeated fixation to clear cytoplasm, the protoplasts were dropped onto microscopic slides. The chromosomes were stained with the fluorescent DAPI dye (4,6-diaminophenylindole). All images were captured digitally using Axio-Cam MRm camera (Zeiss) and AxioVision $40 \mathrm{~V}$ 4.6.3.0 software (Zeiss). Chromosomes were counted from 10-20 metaphases per each plant.

\section{RESULTS AND DISCUSSION}

Most of the putative F1 and F2 hybrids resembled the female parent in terms of wide-spreading stem type, grey to silver bark and the shape of purple leaves although their leaves were bigger. Main branches of these low hybrids showed spiral growth that was typical for $B$. nana while paternal form - B. utilis 'Doorenbos' was characterized by unbranched, columniform growth pattern with long straight trunk. One specimen among F1 popula-

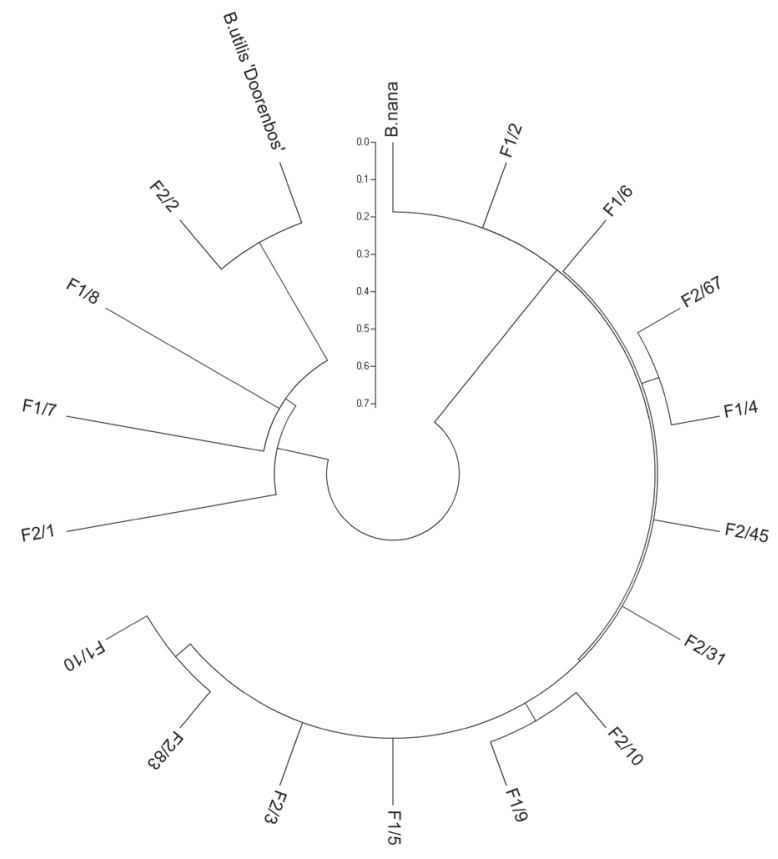

Figure 3. Dendrogram constructed by using RAPD markers following by Neighbor-Joining method

tion (F1/8) was intermediate in the phenotype in relation to parental forms, i.e. it was columniform but had a shorter trunk and its leaves were not as big as for B. utilis 'Doorenbos', but not as small as for B. nana.

Out of the 30 primers used for RAPD-PCR method, only 24 were found to yield reproducible and consistent results, while the rest of the primers resulted in either no amplification or smeared profiles. These 24 decamer primers consistently amplified 242 RAPD fragments (Table 1). The number of bands resolved by one primer ranged from 4 to 18 with an average of 10.1 bands per primer. The size of bands ranged from 280 bp to 3500 bp. Out of the 242 bands scored, 220 (90.9\%) were polymorphic. The number of polymorphic bands per primer ranged from 3 to 17 , the average being 9.2 .

RAPDs are dominant markers, therefore this technique can be used to identify primers displaying hybrid profiles with markers from both parents through which a large number of genotypes could be screened more quickly and cheaply than with other techniques (Williams et al., 1990). Twenty two RAPD primers resulted in the amplification of male parent specific polymorphic bands while 4 and 5 such markers were generated by: OPA09, ARK4 and ARK11. In total, out of the 242 markers, $49(20.2 \%)$ were useful for selecting hybrids based on shared bands in the male parent and offspring. However, 65 of the bands were present in the hybrids but absent in both parents. Non-parental bands observed in progenies might have resulted from DNA recombination or mutation (Darnell, 1990). Moreover, crossing-over during meiosis might have caused the loss of priming sites and thus markers were present in parents but not in offspring (Tyagi et al., 1992). Gel images of RAPD profile of primers OPA10 and ARK7 are given in Figs. 1 and 2.

The Jaccard's pairwise similarity coefficient, calculated for the population of F1 hybrids, ranged from 0.662 to 0.813 with an average of 0.756 and for the F2 hybrids ranged from 0.488 to 0.756 with an average of 0.669 . 
Principal Coordinates (PCoA)

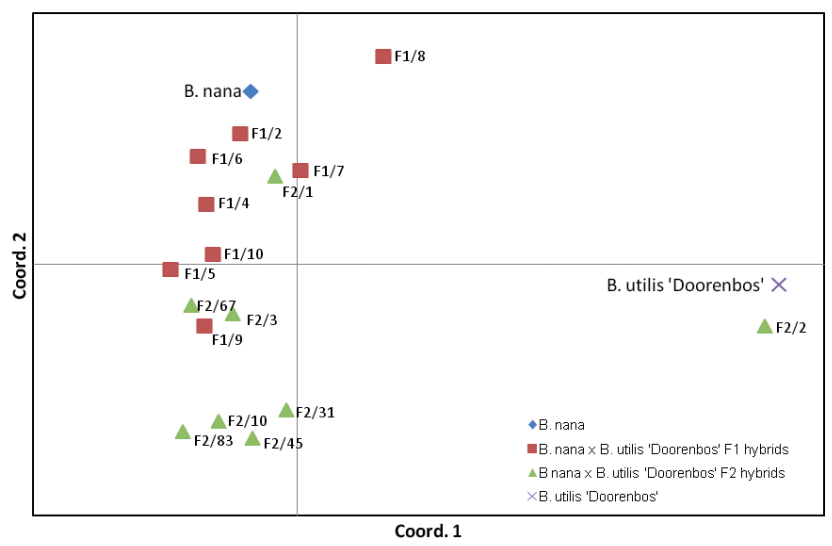

Figure 4. Principal coordinates plot of Betula accessions for the first two principal components estimated with 242 RAPD markers

Such range, especially for the F2 hybrids, demonstrated an existing variability among plants. Parents - B. nana and B. utilis 'Doorenbos' showed the similarity of $52 \%$ between each other and the hybrids shared 75.6\% and $54.3 \%$ similarity to the parents, respectively. The highest value of some genetic measures were calculated for the F2 hybrid population, i.e. the observed number of alleles $(A a=1.73 \pm 0.04)$, the effective number of alleles $(A e=1.52 \pm 0.02)$, the Nei's gene diversity $(H=0.29 \pm 0.01)$, the Shannon's Information Index $(I=0.44 \pm 0.02)$ and the percentage of polymorphic bands $(P=80.5 \%)$ which confirmed higher variability among the F2 hybrids.

The NJ cluster analysis showed that all birch accessions were grouped into two distinct marker-based clusters; cluster I and cluster II with twelve and four hybrid genotypes, respectively (Fig. 3). In the dendrogram, cluster I consisted of the female parent - B. nana and 12 hybrids (F1/2, F1/6, F2/67, F1/4, F2/45, F2/31, $\mathrm{F} 2 / 10, \mathrm{~F} 1 / 9, \mathrm{~F} 1 / 5, \mathrm{~F} 2 / 3, \mathrm{~F} 2 / 83$ and F1/10) and cluster II grouped the male parent $-B$. utilis 'Doorenbos' with 4 hybrids i.e. F2/2, F1/8, F1/7 and F2/1.

The principal component analysis (PCoA) was performed in order to determine the relationships between birch accessions. PCoA revealed that the PC1, PC2, and PC3 accounted for 20.1\%, 9.6\%, and $8.1 \%$ of the variation, respectively. Together, the first three PCs accounted for $37.8 \%$ of the total variation. The $2-\mathrm{D}$ scaling by PCoA was in agreement with the similarity index and the grouping pattern corresponded with that of clustering analysis as shown in the dendrogram. In the 2-D plot most of the hybrids occupied close positions to the female parent (B. nana) and only two progenies (F2/2, F1/8) were placed closer to the male parent $(B$. utilis 'Doorenbos') (Fig. 4). The 2-D plot differentiated the F1 and F2 hybrids into two clusters while F1 progenies placed closer to B. nana.

Ploidy analysis by using direct chromosome counting method revealed that $B$. nana and B. utilis 'Doorenbos' were diploid $(2 n=2 x=28)$ and tetraploid $(2 n=4 x=56)$, respectively (Fig. $5 \mathrm{a}, 5 \mathrm{~b})$. Out of the $16 \mathrm{~F} 1$ and F2 hybrid progenies examined in this study, 13 plants $(81.2 \%)$ were confirmed with accurate chromosome counts as being diploid $(2 \mathrm{n}=2 \mathrm{x}=28)$ and 3 plants (F1/7, F1/8 and F2/2) as triploid with 42 chromosomes (Fig. 5c). No aneuploid cells or aneuploid plants were detected. There seem to be genome rearrangements accompanying the interspecific hybridization that could have resulted in significant deviation from the expected intermediate hybrid genome size. It was confirmed that there is a high degree of incompatibility in artificial birch crosses between parents of different ploidy level but viable crosses are possible (Hagman, 1971). Johnsson (1945) obtained two seedlings with $2 \mathrm{n}=42$ and ten seedlings with $2 \mathrm{n}=56$, both from the same cross involving $B$. pendula $(2 \mathrm{n}=2 \mathrm{x}=28)$ and B. pubescens $(2 \mathrm{n}=4 \mathrm{x}=56)$. Johnsson was inclined to attribute these counts to pollen contamination. However, Hagman (1971) and Eifler (1960) obtained 2n=28 and $2 \mathrm{n}=42$ seedlings from $B$. pendula $\times$ B. pubescens crosses and from the reciprocal crosses seedlings with $2 \mathrm{n}=28,42$ and 56 were obtained. Hagman suggested that $50 \%$ of $B$. pubescens gametes were $\mathrm{n}=14$, the other half had $\mathrm{n}=28$.

In conclusion, combined molecular marker and cytogenetic data can provide more information and clear discrimination of genotypes. RAPD markers allowed to assess the genetic diversity between F1 and F2 hybrids
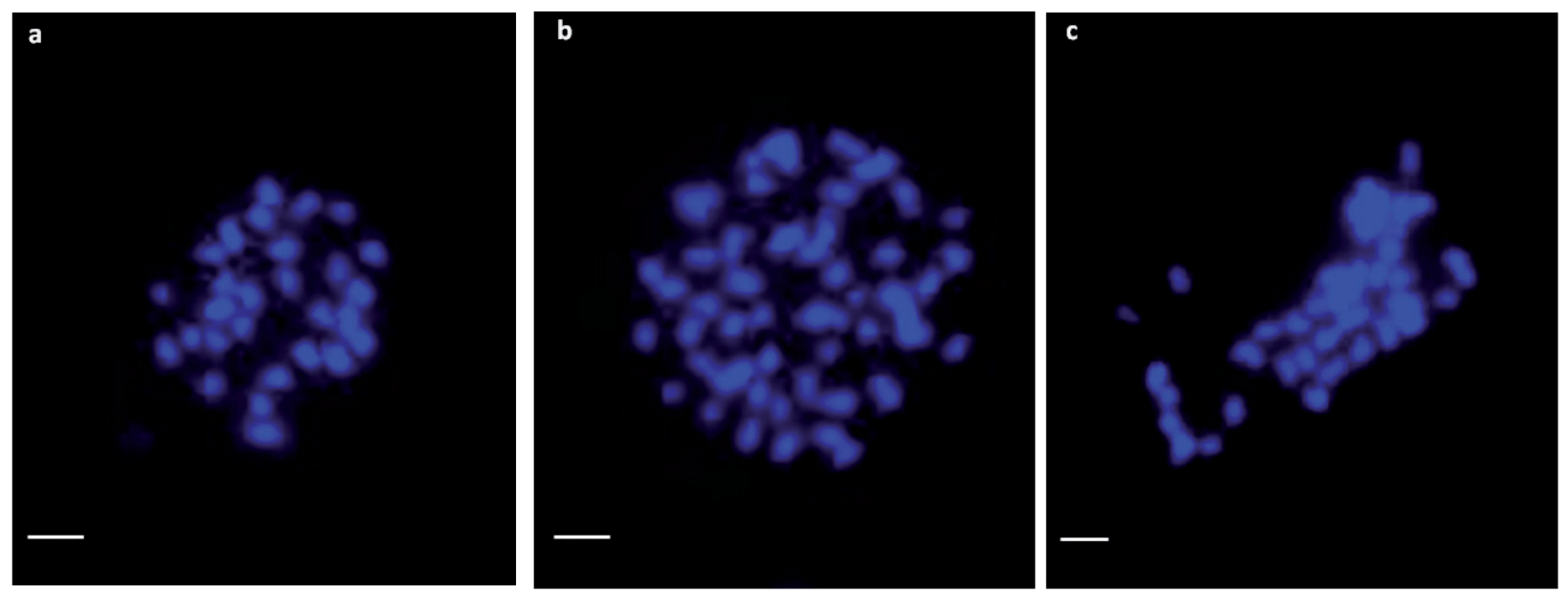

Figure 5. Chromosome number of diploid B. nana and 13 diploid hybrids (a: $2 n=2 x=28$ ), tetraploid B. utilis 'Doorenbos' (b: $2 n=4 x=56)$ and triploid hybrids (F1/7, F1/8, F2/2) (c: $2 n=3 x=42)$.

The chromosomes were isolated from leaf buds and stained with DAPI. Scale bar $=2 \mu \mathrm{m}$. 
of B. nana and B. utilis 'Doorenbos'. Four hybrid plants were clustered together with the male parent $-B$. utilis 'Doorenbos'. Chromosome counting indicated that three plants among them possessed the intermediate chromosome number. In terms of the specimen F1/8, the morphological analysis also indicated intermediate features between B. nana and B. utilis 'Doorenbos'.

\section{Acknowledgments}

This research was supported by the Polish Ministry of Science and Higher Education, grant no. 202914/E/377/M/2013.

\section{REFERENCES}

Anamthawat-Jónsson K (2003) Preparation of chromosomes from plant leaf meristems for karyotype analysis and in situ hybridization. Methods in Cell Science 25: 91-95.

Atkinson MD (1992) Betula pendula Roth (B. verrucosa Ehrh.) and B. pubescens Ehrh. I Ecol 80: 837-870.

Darnell JE, Baltimore D, Lodish IIF (1990) Molecular and cellular biology. Scientific American Books, New York.

Dąbrowska G, Dzialuk A, Burnicka O, Ejankowski W, Gugnacka-Fiedor W, Goc A (2006) Genetic diversity of postglacial relict shrub Betula nana revealed by RAPD analysis. Dendrobiology 55: 1923.

De Groot WJ, Thomas PA, Wein RW (1997) Betula nana L. and Betula glandulosa Michx. Biological Flora of the British Isles. Journal of Ecology 85: 241-264.

Eaker TA, Ranney TG, Viloria ZJ, Mowrey JA (2004) Variation in ploidy level among birch taxa. Plant Breeding \& Evaluation Section. SNA Research conference 49: 548-551.

Eifler I (1960) Untersuchungen zur individuellen Bedingtheit des Kreuzungserfolges zwischen Betula pendula and Betula pubescens. Silvae Genet 9: 159-165.

Ejankowski W, Kunz M (2006) Reconstruction of vegetation Dynamics in "Linje" peat — bog (N Poland) using remote sensing metod. Biodiv Res Conserv 1-2: 111-113.

Felsenstein J (2005) PHYLIP (Pbylogeny Inference Package) version 3.65. Distributed by the author. Department of Genetics, University of Washington, Seattle.
Furlow J (1990) The genera of Betulaceae in the southeastern United States. Journal of the Arnold Arboretum 71: 1-67.

Hagman M (1971) On self and cross incompatibility shown by Betula verrucosa Ehrh. and B. pubescens Ehrh. Commun Inst For Fenn 73: 1.

Järvinen P, Palmé A, Morales LO, Lännenpää M, Keinänen M, Sopanen T, Lascoux M (2004) Phylogenetic relationships of Betula species (Betulaceae) based on nuclear ADH and chloroplast matK sequences. Am J Bot 9: 1834-1845.

Jadwiszczak KA, Drzymulska D, Banaszek A, Jadwiszczak P (2012) Population history, genetic variation and conservation status of the endangered birch species Betula nana L. in Poland. Silva Fennica 46: 465-477.

Johnsson H (1945) Interspecific hybridisation within the genus Betula. Hereditas 31: 163-176.

Nei M, (1973) Analysis of gene diversity in subdivided populations. Proc Natl Acad Sci 70: 3321-3323.

Peakall R, Smouse PE (2006) GENALEX 6: genetic analysis in Excel. Population genetic software for teaching and research. Mol Ecol Notes 6: 288-295.

Roy A, Frascaria N, MacKay J, Bousquet J (1992) Segregating random amplified polymorphic DNAs (RAPDs) in Betula alleghaniensis. Theor Appl Genet 85: 173-180.

Schenk M, Thienpont CN, Koopman W, Gilissen L, Smulders M (2008) Phylogenetic relationships in Betula (Betulaceae) based on AFLP markers. Tree Genet Genomes 4: 911-924.

Thorsson AT, Palsson S, Sigurgeirsson A, Anamthawat - Jonsson K (2007) Morphological variation among Betula nana (diploid), B. pubescens (tetraploid) and their triploid hybrids in Iceland. Ann Bot 99: 1183-1193.

Tsuda Y, Goto S, Ide Y (2004) RAPD analysis of genetic variation within and among four natural populations of Betula maximonicziana. Silvae Genetica 53: 234-239.

Tyagi BR, Ahmed T, Bahl JR (1992) Cytology, genetics and breeding of commercially important Mentha species. Curr Res Med Arom Plants 14: $51-56$.

Williams JGK, Kubelik AR, Livak KJ, Rafalski JA, Tingey SV (1990) DNA polymorphisms amplified by arbitrary primers are useful as genetic markers. Nucleic Acids Res 18: 6531-6535.

Zeng J, Zou Y, Bai J, Zheng H (2003) RAPD analysis of genetic variation in natural populations of Betula alnoides from Guangxi, China. Euphytica 134: 33-41. 